\title{
RESUMO
}

ISSN Digital: 2316-381X

ISSN Impresso: 2316-3321

DOI: 10.17564/2316-381X.2019v7n3p69-82

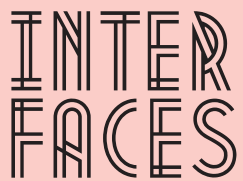

CIENTÍFICAS

\section{O OUTRO LADO DA GUERRA UMA BREVE ANÁLISE SOBRE A EXPERIÊNCIA DA REFUGIADA EM TRÂNSITO NA LÍBIA}

\author{
THE OTHER SIDE OF WAR \\ A BRIEF REVIEW OF THE EXPERIENCE OF \\ THE REFUGEE IN TRANSIT IN LIBYA
}

\section{EL OTRO LADO DE LA GUERRA \\ UN BREVE ANÁLISIS SOBRE LA EXPERIENCIA DE \\ LA REFUGIADA EN TRÁNSITO EN LIBIA}

\section{PALAVRAS-CHAVE}

Refúgio. Líbia. Violência de Gênero. Estudos de Gênero.

A mulher refugiada encontra-se em uma situação duplamente vulnerável em conflitos armados, sofrendo diversos abusos de direitos humanos. As razões da ocorrência da violência de gênero durante guerras são diversas, a ser analisada no presente artigo a violência sexual devido o colapso da ordem social de um Estado, em especial na Líbia. 0 país encontra-se submerso em duas guerras civis paralelas e obstáculos no diálogo entre as partes conflitantes reflete a dificuldade em tomar medidas para proteger os direitos não apenas dos próprios cidadãos, como também dos refugiados e migrantes. Para analisar a experiência da refugiada em trânsito na Líbia, o artigo dividir-se-á em três seções: a primeira visa fazer uma exposição teórica acerca dos conceitos de gênero e sobre violência com base no gênero, enquanto na segunda seção o conflito civil no país será analisado. A terceira seção, por fim, pretende expor a situação das migrantes forçadas que fogem de perseguições em seus países de origem e utilizam a rota da Líbia até a Europa, onde são vítimas de maiores abusos e violência de gênero.

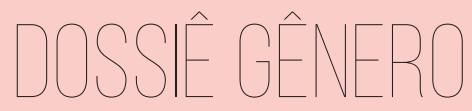




\section{ABSTRACT}

The refugee woman is doubly vulnerable situation of armed conflicts, suffering various human rights abuses. The reasons for the occurrence of gender-based violence during wars are diverse, to be analyzed in this article sexual violence due the collapse of the social order of a state, especially in Libya. The country is submerged in two parallel civil wars and obstacles in the dialogue between the conflicting parties reflects the difficulty in taking measures to protect the rights not only of the citizens themselves, but also of refugees and migrants. In order to analyze the experience of the refugee in transit in Libya, the article will be divided into three sections: the first aims to provide a theoretical exposition about the concepts of gender and gender-based violence, while in the second section the civil war in the country will be analyzed. Finally, the third section aims to expose the situation of forced migrants fleeing persecution in their countries of origin and using the route from Libya to Europe, where they are victims of further abuse and gender-based violence.

\section{KEYWORDS}

Refugee. Libya. Gender-Based Violence. Gender Studies.

\section{RESUMEN}

La mujer refugiada se encuentra en una situación doblemente vulnerable en conflictos armados, sufriendo diversos abusos de derechos humanos. Las razones de la ocurrencia de la violencia de género durante las guerras son diversas, a ser analizada en el presente artículo la violencia sexual debido al colapso del orden social de un Estado, en especial en Libia. El país se encuentra sumergido en dos guerras civiles paralelas y obstáculos en el diálogo entre las partes conflictivas refleja la dificultad en tomar medidas para proteger los derechos no solo de los propios ciudadanos, sino también de los refugiados y migrantes. Para analizar la experiencia de la refugiada en tránsito en Libia, el artículo se dividirá en tres secciones: la primera pretende hacer una exposición teórica acerca de los conceptos de género y sobre la violencia basada en el género, mientras que en la segunda sección el conflicto civil en el país será analizado. La tercera sección, por último, pretende exponer la situación de las migrantes forzadas que huyen de persecuciones en sus países de origen y utilizan la ruta de Libia hacia Europa, donde son víctimas de mayores abusos y violencia de género.

\section{PALABRAS CLAVE}

Refugio; Libia; Violencia de género, estudios de género. 


\section{INTRODUÇ̧̃̃o}

A violência com base no gênero, em especial a violência sexual durante períodos de guerra, não é um fenômeno novo, sendo documentado com crescente regularidade desde o século XX. Por exemplo, o estupro e a prostituição forçada durante a Segunda Guerra Mundial é de amplo conhecimento, particularmente o estupro de alemãs por soldados soviéticos, bem como a escravidão de cerca de 400 mil mulheres pelo exército japonês. Milhares de estupros têm sido documentados nos conflitos da Líbia, Ruanda, Somália e do Sudão. Isto ocorre, pois, na maioria dos conflitos armados a violência sexual exerce função tácita de intimidação, degradação, humilhação e tortura do inimigo (WEITSMAN, 2008).

Todavia, a violência de gênero em alguns conflitos pode ser limitada, apesar da violência generalizada contra civis. Em alguns conflitos, a violência contra mulheres assume a forma de escravidão sexual, pelo que as mulheres são sequestradas para servir como parceiras sexuais de combatentes por longos períodos; em outros, toma a forma de abusos contra migrantes deslocadas dentro do próprio território. Pode, bem como, haver certa variação na extensão e forma da violência sexual na guerra: ela varia em prevalência e forma em guerras civis, guerras interestatais, guerras étnicas, além de não-étnicas (WOOD, 2006).

Evidências sugerem que a violência sexual em situações de conflito armado é muitas vezes arbitrária e não sistemática, em parte como resultado da quebra de sistemas governamentais, das normas sociais e do aparato legal (VANN; WARD, 2002). A situação é agravada, pois mulheres e meninas são marginalizadas na maioria das sociedades. Isso, juntamente com a violência do conflito e suas dimensões de gênero, muitas vezes leva à uma maior vulnerabilidade e a determinados tipos de perda, violência e danos contra a mulher (MUZURANA; PROCTOR, 2013).

Os abusos generalizados por grupos armados, contrabandistas, traficantes e grupos criminosos organizados na Líbia, bem como a exploração sistemática, a ilegalidade e os conflitos armados estão empurrando centenas de milhares de migrantes, requerentes de asilo e refugiados a arriscarem suas vidas, tentando atravessar o Mar Mediterrâneo. Dados coletados pela Anistia Internacional evidenciam casos de violência sexual, assassinato, tortura e perseguição religiosa pelas rotas de contrabando humano na Líbia. Em 2016, pelo menos 90 refugiadas e migrantes recebidas em campos na Itália afirmaram terem sido abusadas pelos citados grupos criminosos (AMNESTY INTERNATIONAL, 2016).

Na maioria das ocasiões elas são entregues a estes grupos após a entrada na Líbia pelas fronteiras do sul do país ou em grandes cidades de trânsito ao longo das rotas de migração, como Ajdabya e Sabha. Por vezes, os próprios contrabandistas mantêm as migrantes e refugiadas em áreas remotas do deserto, obrigando-as a chamar suas famílias para o pagamento do resgate. Com conflitos armados em curso entre várias coalizões de grupos armados e o estabelecimento de dois governos paralelos que defendem o poder, a detenção sistemática de estrangeiros continua (AMNESTY INTERNATIONAL, 2016).

A tortura e outros maus-tratos nos centros de detenção de imigração permaneceram generalizados. Em muitos casos, os migrantes e refugiados que buscavam atravessar o Mediterrâneo foram submetidos a ataques prolongados em tais instalações após a sua intercepção e prisão pela guarda costeira líbia ou milícias que agem por iniciativa própria na ausência de instituições estatais fortes. 
As mulheres que se encontram nessas instalações, as quais em sua grande maioria não possuem guardas femininas, são vulneráveis a violência e assédio sexual (DEARDEN, 2017).

O estupro pode ser utilizado de forma não sistemática, tendo em vista a vulnerabilidade das mulheres migrantes, forçadas a se deslocarem por fronteiras transnacionais devido a perseguições com motivações diversas, entre elas inclusive a própria violência de gênero. 0 caso a ser estudado no presente trabalho refere-se às inúmeras denúncias que emergiram após a derrubada do presidente Muammar Gaddafi sobre violência sexual contra mulheres refugiadas em trânsito pela Líbia.

Por conseguinte, o artigo tem a intenção de responder a seguinte pergunta: visto que a violência de gênero ocorre devido à posição marginal ocupada pela mulher na sociedade, como o conflito na Líbia afeta a experiência da refugiada em trânsito pelo país?

A hipótese adotada é de que, dentro de um grupo social já marginalizado, o fato da migrante ser forçada a deslocar-se por entre fronteiras devido à perseguição em seu próprio Estado torna-a ainda mais vulnerável à violência. A Líbia, um Estado com instituições políticas, sociais e econômicas em colapso mostra-se incapaz de proteger não somente seus cidadãos, sendo ela uma produtora de refugiados, como também daqueles em trânsito por seu território. Desta forma, o conflito civil na Líbia perpetua, reforça e agrava a condição marginal da refugiada, expondo-a a mais violência que aquelas sofridas em seu país de origem.

A fim de responder à pergunta proposta, foi utilizado o método qualitativo de pesquisa, além do estudo de caso da experiência da mulher refugiada em trânsito na Líbia. 0 artigo dividir-se-á em três seções: a primeira visa fazer uma exposição teórica acerca dos conceitos de gênero de autoras como Mary Mikkola (2016) e Laura Sjoberg e Sandra Via (2010), e sobre violência com base no gênero, utilizando principalmente os autores Dyan Muzarana e Keith Proctor (2013), Jeanne Ward e Mendy Marsh (2006), além de Henry Quest (2016), de forma que seja possível compreender os problemas enfrentados pelas refugiadas no país mencionado.

Para este fim, também, buscar-se-á analisar, na segunda seção, o conflito desde o colapso gradual do Estado com a queda do presidente Muammar Gaddafi para que então, na terceira seção, seja exposta a situação das migrantes forçadas que fogem de perseguições em seus países de origem e utilizam a rota da Líbia até a Europa, onde são vítimas de maiores abusos e violência.

\section{A VIOLÊNCIA CONTRA A MULHER EM TEMPOS DE GUERRA: 0 GÊNEROE SUAS IMPLICAÇÕES}

Para que seja possível analisar a experiência da migrante forçada na guerra da Líbia, faz-se necessário o entendimento das implicações do conceito de gênero, tanto em conflitos como em tempos de paz. De acordo com Mary Mikkola (2016), historicamente diversas feministas têm argumentado que o termo mulher distingue-se das variáveis biológicas que levam em consideração os aspectos anatômicos do sexo - como a genitália. Para estas estudiosas, o termo a ser considerado quando pensado a mulher deveria depender não de fatores biológicos, mas de causas sociais e culturais. Desta forma, diferencia-se o sexo (feminino ou masculino) do gênero (mulher ou homem). 
O motivo pelo qual diversas feministas identificam a diferença entre fatores biológicos do sexo das características de gênero deu-se de forma a contrapor o determinismo biológico ou a visão de que a biologia é um “destino". Este determinismo foi muitas vezes utilizado para, por exemplo, justificar e perpetuar a negação de direitos políticos às mulheres no século XIX. Para rebater os argumentos de que a mulher não necessitava de direitos devido aos seus aspectos biológicos, algumas feministas enunciavam que as diferenças psicológicas e comportamentais entre homens e mulheres possuíam causas sociais e não biológicas, adquiridas ao longo do tempo (MIKKOLA, 2016).

0 gênero é mais aparente nas diferenças sociais entre homens e mulheres; estas diferenças moldam como os indivíduos são vistos e como eles veem a si mesmos. Por meio da interação com outras variáveis - como etnia, raça, classe social e orientação sexual - o gênero age de forma a informar uma identidade. Entretanto, o gênero é mais que apenas a identidade dos indivíduos: é um meio de categorizar, ordenar e simbolizar o poder, estruturando hierarquicamente as relações entre diferentes categorias de pessoas e diferentes atividades humanas, simbolicamente associadas à masculinidade e à feminilidade, valorizando um sobre o outro (MUZARANA; PROCTOR, 2013).

Assim, o gênero é associado às características sociais que se presumem ser relacionadas às categorias da mulher e do homem; características associadas com a masculinidade seriam a força física, a racionalidade, a agressão, a dominação e a liderança. Por outro lado, as características relacionadas à mulher em geral são a vulnerabilidade, a emoção, a passividade e a submissão. Sendo assim, feminizar algo ou alguém teria o significado de subordinar tal indivíduo, entidade política ou ideia, pois traços percebidos como femininos seriam inferiores na hierarquia social (SJOBERG; VIA, 2010).

Há, portanto, um consenso quanto à construção social de gênero e suas características. Todavia, algumas questões como quais práticas sociais constroem o gênero, o que são construções sociais e o que significa ao certo o termo gênero, ainda são controversas dentro do próprio núcleo feminista. Ao levarmos em consideraçãoo gênero como fator socialmente construído, é preciso analisar a socialização do gênero, pois a fêmea torna-se mulher por meio de um processo de ensinamento social, onde adquiri certos traços e aprende sobre o comportamento feminino (MIKKOLA, 2016).

Apesar de o gênero ser dividido como estereótipos, normas comportamentais e regras atribuídas ao homem e à mulher (masculinidade e feminilidade), ele não segue tais expectativas baseadas apenas no gênero, pois o comportamento humano varia, logo as categorias de gênero bem como variam conforme o lugar, a cultura, o tempo e a religião de onde estas práticas são realizadas. Contudo, mesmo estas variáveis, mudando por meio de diferentes contextos sócio-políticos, a subordinação do gênero continua sendo um fator constante na vida política e social pelo tempo e o espaço (SJOBERG; VIA, 2010).

Em suma, o gênero é um arranjo de discursos que moldam, constroem e dão significado à vida política e social. A forma de distinguir o gênero como um arranjo de discursos e não apenas um discurso indica que ele é vivenciado em contextos e culturas que diferem entre si (SJOBERG; VIA, 2016). Essa definição evita críticas, em especial sobre o realismo de gênero; argumenta-se que esta corrente do feminismo não leva em consideração as diferenças entre mulheres, que distinguem entre si devido à raça, à cultura e à classe, além de postular um ideal normativo de feminilidade (MIKKOLA, 2016).

Os papeis de gênero organizam autoridades, direitos, responsabilidades, acesso a recursos e opções 
de vida entre as linhas que demarcam estes grupos. Os sistemas de poder de gênero requerem instituições políticas, sociais, econômicas, culturais, legais e educacionais que atualizem e sustentem esta distribuição de poder e, por vezes, justificam o acesso e tratamento desigual entre os gêneros (MUZARANA; PROCTOR, 2013). É possível concluir, portanto, que o homem e a mulher possuem experiências diferentes nos contextos políticos e sociais. Desta forma, o gênero, bem como, molda e é moldado por eventos e atores envolvidos em conflitos armados, processos de paz e de reconstrução após o conflito.

Tanto os homens quanto as mulheres vivenciam fenômenos similares durante conflitos armados; todavia, o modo como cada grupo experiência a violência é influenciado por seus papéis de gênero. Isto ocorre, pois, mulheres e homens simbolizam coisas diferentes em suas comunidades e são perseguidos de formas diversas. A posição marginalizada da mulher na maioria das sociedades, acoplada à violência dos conflitos acarreta a um aumento da vulnerabilidade deste grupo em tempos de guerra. É possível observar esta tendência no acesso reduzido das mulheres a recursos, a restrição à mobilidade, o acesso desigual a mecanismos de proteção, entre outros. Todos estes fatores influenciam a habilidade das mulheres e garotas em sobreviverem e se recuperarem de conflitos armados (MUZARANA; PROCTOR, 2013).

A violência contra a mulher pode ser normativa, ou seja, práticas rotineiras de coerção e dominação. A violência normativa refere-se ao fenômeno de dominação da mulher por parte do homem, que pretende controlar todos os aspectos de sua vida. Além disso, tal dominação é justificada por meio de normas sociais, religiosas e culturais. A natureza desta dominação varia, bem como, entre classes, castas, raças e etnias, mas as normas de gênero na maioria das sociedades colocam a mulher em posição inferior que a de homens da mesma categoria social (MUZARANA; PROCTOR, 2013).

Os papéis e as expectativas de gênero, a objetificação sexual e as discrepâncias de poder e status têm legitimado e perpetuado a violência contra a mulher. Por conseguinte, a violência com base no gênero é definida como qualquer ato que resulte de agressões físicas, sexuais ou psicológicas que venha a causar qualquer dano na mulher, seja na vida pública ou privada. Esta definição surgiu na Conferência de Pequim em 1995 e representou o consenso internacional em conceituar as dinâmicas da violência de gênero contra a mulher, incluindo o abuso sexual infantil, o estupro e a violência entre parceiros íntimos. 0 termo baseado no gênero ou com base no gênero é usado, pois, a violência é moldada pelos papéis de gênero e status em determinada sociedade. (PIRLOTT; RUSSO, 2006).

Devido à naturalização de algumas formas de violência, as consequências dela durante conflitos e guerras têm sido historicamente ignoradas e muitas vezes não foram ou não são reconhecidas como violações de direitos humanos. Outra consequência da naturalização da dominação masculina sobre a mulher dá-se por meio do controle da reprodução feminina durante tempos de paz, que pode resultar em situações de violência sexual em períodos de conflito, consideradas como formas legítimas de estratégia militar. Além disso, em períodos de guerra a violência contra a mulher é usada para demonstrar o poder do homem e reafirmar a masculinidade não apenas sobre as mulheres, mas também sobre os parentes de sexo masculino da vítima (MUZARANA; PROCTOR, 2013).

A violência de gênero em tempos de conflitos pode ocorrer devido a diversos motivos: o intercâmbio masculino por meio da violência contra a mulher, o simbolismo do gênero nas sociedades, 
o multiplicador da violência, entre outros. A primeira razão refere-se à violência como forma de comunicação entre homens, sendo estratégias de controle, dominação e humilhação a fim de desafiar o poder e a possessão de outros homens, fundamentando as hierarquias sociais e políticas de gênero (MUZARANA; PROCTOR, 2013).

O simbolismo do gênero e a punição da transgressão das mulheres dizem respeito ao gênero como sistema simbólico que as infunde de significados culturais, religiosos e políticos. Em muitas sociedades, as mulheres representam suas famílias e comunidades por meio de seus corpos e comportamentos. A violência sexual, portanto, age como um ataque à masculinidade daqueles que deveriam proteger suas filhas, mulheres, ou outros membros femininos de sua família (MUZARANA; PROCTOR, 2013).

Os multiplicadores da violência de gênero fazem menção às múltiplas dimensões de sofrimento enfrentadas pelas mulheres, sejam elas físicas, psicológicas ou econômicas e seus status marginalizados na sociedade. Estes multiplicadores levam a crer que alguns crimes vulnerabilizam as mulheres ainda mais contra as violações de direitos humanos, havendo uma exposição adicional à violência durante e após um conflito (MUZARANA; PROCTOR, 2013).

A violência de gênero contra mulheres em tempos de conflito armado não é um fenômeno novo, porém tem sido historicamente ignorada. De acordo com Marsh e Ward (2006), dados mostram um aumento dos estudos sobre o fenômeno nos últimos dez anos devido a diversas razões possíveis, entre elas a maior atenção dada ao assunto por organizações internacionais, o aumento da conscientização por meio de movimentos feministas e a mudança da natureza da guerra, tornando as mulheres ainda mais vulneráveis. A maior parte dos conflitos agora ocorre dentro dos próprios Estados, patrocinados por milícias e grupos terroristas ou pelo próprio governo, onde o alvo principal torna-se os civis. Todavia, a violência contra civis não é um produto, mas sim uma estratégia necessária ao conflito (MUZARANA; PROCTOR, 2013).

A violência contra a mulher é uma escolha estratégia durante a guerra, baseada e sustentada por meio da manipulação das identidades de gênero (MUZARANA; PROCTOR, 2013). Esta estratégia de guerra muitas vezes surge como resultado de discursos sociais que perpetuam a posição de dominância do homem e a necessidade de exercê-la para serem "homens de verdade". O corpo feminino surge como símbolo da integridade de uma comunidade ou nação (QUEST, 2016), representa o potencial reprodutivo do inimigo e serve para perpetuar o intercâmbio masculino e o simbolismo do gênero durante o conflito armado.

As motivações da violência de gênero durante guerras, a ser trabalhada no presente artigo a violência sexual, são variadas; pode ocorrer devido ao colapso da ordem social e moral, onde a violência não é limitada aos combatentes, mas podem ser perpetuadas, também, por homens da comunidade local que se aproveitam do caos do conflito para cometer violência sexual sem o temor da punição (MARSH; WARD, 2006). 0 caso da Líbia, a ser explorado nas próximas seções, mostra-se um exemplo pertinente da propagação da violência sexual, tanto de civis quanto das migrantes em trânsito no país, devido ao colapso das instituições estatais com a guerra.

A violência sexual com base no gênero também pode ser sistemática, realizada pelas milícias com o propósito explícito de desestabilizar a população e destruir os laços entre as famílias e a comunida- 
de. Ocorre, bem como, para conter a resistência ao instalar o medo nas oposições ao grupo armado ou nas comunidades locais como um todo. Nestes dois casos, o corpo da mulher é utilizado como “envelopes para enviar mensagens ao inimigo" (MARSH; WARD, 2006, p. 4).

A vulnerabilidade da mulher e os impactos do conflito armado também são vistos em todas as fases do deslocamento forçado, como observado na Líbia. A violência é cometida por bandidos, grupos insurgentes e guardas de fronteiras, pois, sem dinheiro ou outros recursos, mulheres e crianças deslocadas podem ser compelidas a submeterem-se aos homens em troca de passagem segura, comida e abrigo, sendo, bem como, alvos de tráfico.

\section{UM ESTADO SEM LEI: 0 COLAPSO DA LÍBIA}

A Líbia é um país localizado no norte da África, dividindo fronteiras com o Egito, a Tunísia e a Alegria, banhado ao norte pelo Mar Mediterrâneo, sendo 90\% de seu território composto por desertos². A Líbia, anterior à queda de Muammar Gadaffi, não era considerada uma democracia eleitoral, visto como o poder teoricamente recaia ao sistema de comitês da população, indiretamente eleito pelo Congresso Geral do Povo; porém, na prática estas estruturas eram manipuladas de forma a perpetuar a dominância de Gaddafi no governo.

Os partidos políticos tornaram-se ilegais desde a Revolução de 1969, quando um grupo armado, liderados por Gaddafi, tomaram o poder do então Rei Idris. Qualquer tipo de organização política era punível a prisão ou a sentenças de morte. De acordo com o Índice de Percepção da Corrupção, em 2009 a Líbia ocupou a colocação 130 dos 180 países analisados pela pesquisa (FREEDOM HOUSE, 2011).

Protestos generalizados em Benghazi em fevereiro de 2011 levaram ao choque entre forças de segurança e a população civil; os protestos logo escalaram para uma rebelião em todo o país, onde forças opositoras ao regime de Gaddafi estabeleceram um governo interino nomeado Conselho Nacional de Transição (BAKER, 2011). Ainda em fevereiro, o Conselho de Segurança das Nações Unidas (CSNU) congelou os recursos de Gaddafi, o que levou o líder a retaliar por meio do domínio de diversas cidades antes securitizadas pelas Nações Unidas (WYATT, 2011). Após campanhas de bombardeio aéreo por forças da Organização do Tratado do Atlântico Norte (OTAN), o governo de Gaddafi anunciou um cessar fogo que foi rejeitado pelos rebeldes, visto como os ataques militares continuaram pelo país (NBC NEWS, 2011).

Em setembro de 2011, o Conselho Nacional de Transição foi reconhecido pela Organização das Nações Unidas (ONU) como o representante legal da Líbia, substituindo o governo de Gaddafi; este se manteve no poder, ainda que contra as resoluções da ONU, até outubro de 2011, quando foi capturado e morto na cidade de Sirte (GAMAL; GAYNOR, 2011). A Líbia tem lutado para reconstruir as instituições estatais frente a crescente violência desde a morte do presidente, visto como a força das milícias rebeldes tem aumentado - aproximadamente 1.700 grupos armados, incluindo combatentes leais ao Estado Islâmico, lutam pelo poder no país.

2 Dados coletados do The World Factbook de 2016, uma publicação anual da Central Intelligence Agency (CIA) dos Estados Unidos com informações de base sobre diversos países do mundo. 
A Câmara dos Deputados tem tentado consolidar sua legitimidade como o poder governante, todavia o Congresso Nacional coloca-se como governo rival na cidade de Tripoli, com o apoio das milícias (COUNCIL..., 2017), evidenciando como o sistema legal pós-revolução mantém-se em fluxo instável entre entidades estatais e não-estatais.

Os anos após a queda de Gaddafi ofereceram tanto desafios quanto oportunidades para a reconstrução de um Estado na Líbia. Entretanto, os desafios têm se mostrado mais difíceis de serem superados, visto a dificuldade em unificar as divergências políticas entre os diversos atores que atuam no país. O diálogo pacífico é dificultado pelas discordâncias regionais que resultam em duas guerras civis paralelas que ocorrem em toda a Líbia (EL-GAMATY, 2016).

Esses obstáculos no diálogo entre as duas partes conflitantes refletem a dificuldade em tomar medidas para proteger os direitos não apenas os próprios cidadãos da Líbia, como também dos refugiados e migrantes. Antes um país altamente receptor de migrantes, com o colapso das instituições estatais cerca de 800 mil migrantes fugiram do país, principalmente para a Tunísia e o Egito, ou para seus países de origem. Ainda assim, desde 2014 a Líbia é o principal destino dos migrantes em trânsito devido à sua instabilidade política e fracos controles de fronteiras, usando-as como uma área primária de fuga do Mediterrâneo à Europa. Além disso, mais de 350 mil pessoas foram deslocadas internamente até agosto de 2016 em virtude dos conflitos armados no país ${ }^{3}$.

Com a exposição do cenário atual do conflito líbio, torna-se possível a compreensão da vulnerabilidade daquelas migrantes forçadas que utilizam a rota do Mediterrâneo para alcançarem a Europa. 0 colapso das instituições governamentais em dois grupos armados em constante discordância leva à falha da proteção dos direitos tanto dos cidadãos - que como mostrado anteriormente, amontam um total de 350 mil deslocados internos - quanto dos refugiados em trânsito no país.

\section{A VIOLÊNCIA DE GÊNERO NA LÍBIA: OS ABUSOS SOFRIDOS PELAS MIGRANTES FORÇADAS}

O contrabandista era bom comigo, mas ele gostava de usar as mulheres. Sei que ele usou três eritreias. Ele as estuprou enquanto elas choravam. Aconteceu pelo menos duas vezes. Algumas mulheres não tinham dinheiro para pagar o resgate, então aceitavam dormir com os contrabandistas. ${ }^{4}$ (Depoimento de um refugiado somali à Amnistia Internacional, 2015).

Os abusos generalizados por grupos armados, contrabandistas, traficantes e grupos criminosos organizados na Líbia, bem como a exploração sistemática, a ilegalidade e os conflitos armados estão forçando centenas de milhares de migrantes, requerentes de asilo e refugiados a arriscarem suas vidas

3 Dados coletados do The World Factbook de 2016, da CIA.

4 No original: The smuggler was nice to me but he liked to use women. I know that he used three Eritrean women. He raped them and they were crying. It happened at least twice. Some of the women don't have money to pay the ransom so they accept to sleep with the smugglers. Os depoimentos de diversas refugiadas estão disponíveis para leitura no relatório da Amnistia Internacional: http://www.amnesty.eu/content/assets/Reports_and_Briefings_2015/Libya_is_full_of_cruelty.pdf. Acesso em: 20 jun. 2017.

Interfaces Científicas - Direito • Aracaju • V.7 • N.3 • p. 69 - 82 • Julho - 2019 
na tentativa de atravessar o Mar Mediterrâneo, sendo que somente em 2015, mais de 1.700 pessoas morreram tentando alcançar a Europa pela rota mediterrânea (AMNESTY INTERNATIONAL, 2016).

Na maioria das vezes, estes migrantes são entregues a grupos criminosos após a entrada na Líbia pelas fronteiras do sul do país ou em grandes cidades de trânsito ao longo das rotas de migração, como Ajdabya e Sabha. Às vezes, os próprios contrabandistas mantêm os migrantes e refugiados em áreas remotas do deserto, obrigando-os a chamarem suas famílias para o pagamento de resgates. Devido aos conflitos armados em curso entre várias coalizões de grupos armados e o estabelecimento de dois governos paralelos que defendem o poder, a detenção sistemática de estrangeiros para as infrações relacionadas com a migração têm aumentado (AMNESTY INTERNATIONAL, 2016).

A tortura e outros maus-tratos nos centros de detenção de imigração permaneceram generalizados. Em muitos casos, os migrantes e refugiados que tentam atravessar o Mediterrâneo são submetidos a ataques prolongados em tais instalações após a sua intercepção e prisão pela guarda costeira líbia ou milícias que agem por iniciativa própria na ausência de fortes instituições do estado. As mutheres que se encontram nessas instalações, que não têm guardas femininas, são ainda mais vulneráveis a violência e assédio sexual (DEARDEN, 2017).

À medida que a violência continua na Líbia, países vizinhos, incluindo Argélia, Tunísia e Egito, têm isolado suas fronteiras e imposto requisitos de entrada mais rigorosos devido ao temor do spill over do conflito. Os migrantes e os refugiados que não são capazes de obter vistos válidos por terem seus passaportes roubados ou confiscados por contrabandistas ou gangues criminosas líbias muitas vezes são deixados sem uma alternativa viável a embarcar na perigosa rota marítima para a Europa.

Evidências sugerem que a violência sexual em situações de conflito armado é muitas vezes arbitrária e não sistemática, em parte como resultado da quebra de sistemas governamentais, das normas sociais e do aparato legal (VANN; WARD, 2002). A situação é agravada, pois mulheres e meninas são marginalizadas na maioria das sociedades. Isso, juntamente com a violência do conflito e suas dimensões de gênero, muitas vezes pode levar a uma maior vulnerabilidade e a determinados tipos de perda, violência e danos (MUZURANA; PROCTOR, 2013).

A Amnistia Internacional (2016) recebeu relatórios, contendo detalhes sobre mulheres que foram abusadas sexualmente por contrabandistas ou grupos criminosos ao longo das rotas de migração mediterrânea. Em alguns casos, as refugiadas que se mostravam incapazes de pagar o resgate foram coagidas ao sexo forçado em troca da liberdade ou autorizadas a continuar a jornada.

A organização entrevistou 15 refugiadas, a maioria das quais alegam ter vivido em perpétuo temor de violência sexual ao longo da viagem à costa líbia. Muitas disseram que a violência era tão comum que tomavam pílulas anticoncepcionais antes de viajar para evitar engravidar como resultado. Equipes médicas, bem como psicólogos e assistentes sociais em três centros de acolhimento visitados pela Amnistia na Sicília e na Puglia, cidades italianas, confirmaram que as mulheres relatavam sofrer um alto nível de violência sexual durante a jornada.

Por conseguinte, na ausência da instituição estatal de sua nacionalidade para resguardar seus direitos fundamentais, a migrante forçada durante o trânsito até o país que pretende solicitar refúgio encontra-se à mercê da proteção de outro Estado. Tendo em vista os dados expostos 
nesta e nas seções anteriores, é possível concluir que a Líbia, principal rota africana à Europa, é incapaz de assegurar os direitos mínimos destas refugiadas, acarretando em sua vulnerabilidade e exposição à violência de gênero.

\section{CONSIDERAÇÕES}

Como exposto nas seções anteriores, os papeis de gênero organizam autoridades, direitos, responsabilidades, acesso a recursos e opções de vida entre as linhas que demarcam estes grupos. Os sistemas de poder de gênero requerem instituições políticas, sociais, econômicas, culturais, legais e educacionais que atualizem e sustentem esta distribuição de poder, por vezes, justificam o acesso e tratamento desigual entre os gêneros (MUZARANA; PROCTOR, 2013). Sendo assim, posição marginalizada da mulher na hierarquia de poder do gênero torna-a vulnerável não apenas à violência sexual, como também à desigualdade social, econômica e política.

Tanto os homens quanto as mulheres vivenciam fenômenos similares durante conflitos armados; todavia, o modo como cada grupo experiencia a violência é influenciado por seus papeis de gênero. Portanto, a posição marginal da mulher na maioria das sociedades, agregada à violência da guerra acarreta a um aumento da vulnerabilidade deste grupo durante conflitos armados. É possível observar esta tendência no acesso reduzido das mulheres a recursos, a restrição à mobilidade, o acesso desigual a mecanismos de proteção, entre outros (MUZARANA; PROCTOR, 2013).

Os motivos da ocorrência da violência de gênero durante guerras são diversos. Foi trabalhada no presente artigo a violência sexual devido ao colapso da ordem social de um Estado, no caso estudado a Líbia. O país encontra-se submerso em duas guerras civis paralelas, onde atores estatais e não-estatais lutam pelo controle do governo. Obstáculos no diálogo entre as duas partes conflitantes no país reflete a dificuldade em tomar medidas para proteger os direitos não apenas os próprios cidadãos da Líbia, como também dos refugiados e migrantes. A Amnistia Internacional tem recebido relatórios, contendo detalhes sobre os abusos sexuais sofridos pelas migrantes forçadas por contrabandistas ou grupos criminosos ao longo das rotas de migração.

A mulher refugiada, portanto, encontra-se em uma situação duplamente vulnerável. Visto como seu próprio Estado foi incapaz de assegurar seus direitos humanos básicos, ela é forçada a fugir por entre fronteiras, muitas vezes sem os recursos necessários para uma viagem segura. Na ausência de uma instituição estatal para resguardar seus direitos, a migrante forçada durante o trânsito até o país que pretende solicitar refúgio encontra-se à mercê da proteção de outro Estado.

É possível concluir que, tendo em vista os dados expostos nas seções anteriores, a Líbia é incapaz de assegurar os direitos mínimos destas refugiadas, fazendo com que suas experiências na rota até o Mediterrâneo sejam inseguras em demasia. Acoplada à sua posição inferior tanto de mulher na hierarquia de gênero, quanto ao seu status de migrante forçada, a refugiada torna-se duplamente suscetível a diversas formas de violência de gênero no trânsito da Líbia à Europa, inclusive a sexual. 


\section{REFERÊNCIAS}

AMNESTY INTERNATIONAL. Libya is full of cruelty: stories of abduction, sexual violence and abuse from migrants and refugees. 2015. Disponível em: http://www.amnesty.eu/content/assets/Reports_ and_Briefings_2015/Libya_is_full_of_cruelty.pdf. Acesso em: 20 jun. 2017.

AMNESTY INTERNATIONAL. Refugees and migrants fleeing sexual violence and abuse and exploitation in Libya. 2016. Disponível em: https://www.amnesty.org/en/latest/news/2016/07/refugees-andmigrants-fleeing-sexual-violence-abuse-and-exploitation-in-libya/. Acesso em: 20 jun. 2017.

BARKER, Anne. Time running out for cornered Gaddafi. 2011. Disponível em: http://www.abc.net. au/news/2011-02-24/time-running-out-for-cornered-gaddafi/1955842. Acesso em: 12 jul. 2017.

CENTRAL INTELLIGENCE AGANCY. The Wold Factbook: Libya. 2016. Disponível em: https://www. cia.gov/library/publications/the-world-factbook/geos/ly.html. Acesso em: 12 jul. 2017.

COUNCIL ON FOREIGN RELATIONS. Civil War in Libya. 2017. Disponível em: https://www.cfr.org/ global/global-conflict-tracker/p32137\#!/conflict/civil-war-in-libya. Acesso em: 12 jul. 2017.

DEARDEN, Lizzie. Harrowing footage exposes 'inhuman' treatment of refugees trapped in Libya. 2017. Disponível em: http://www.independent.co.uk/news/world/africa/ross-kemp-libya-migranthell-video-documentary-sky-refugees-torture-rape-detention-mediterranean-a7587811.html. Acesso em: 20 jun. 2017.

EL GAMAL, Rania; GAYNOR, Tim. Gaddafi killed as Libya's revolt claims hometown. 2011. Disponível em: https://af.reuters.com/article/topNews/idAFJOE79J09020111020. Acesso em: 12 jul. 2017.

EL-GAMATY, Guma. Libya: The story of the conflict explained. 2016. Disponivel em: http://www.aljazeera. com/news/2016/04/libya-story-conflict-explained-160426105007488.html. Acesso em: 12 jul. 2017.

FREEDOM HOUSE. Freedom in the World. 2010. Disponível em: https://freedomhouse.org/report/ freedom-world/2010/libya?page=22\&year=2010\&country=7862. Acesso em: 12 jul. 2017.

MARSH, Mendy; WARD, Jeanne. Sexual violence against women and girls in war and its aftermath: Realities, Responses and Ressources Required. Paper para Symposium on Sexual Violence in Conflict and Beyond. Brussels, junho 2006.

MUZURANA, Dyan; PROCTOR, Keith. Gender, conflict and peace. Occasional Paper, World Peace Foundation, October 2013. 
NBC NEWS. Gadhafi blasts 'crusader' aggression after strikes, 2011. Disponível em: http://www. nbcnews.com/id/42164455/ns/world_news-mideastn_africa\#.WWaV4oTyvIV. Acesso em: 12 jul. 2017.

PIRLOTT, Angela; RUSSO, Nancy Felipe. Gender-Based Violence: Consepts, Methods, and Findings. Annals of the New York Academy of Sciences, v. 1087, Violence and Exploitation Against Women and Girls, p. 178-205.

QUEST, Henry. Militarized masculinity in the context of disarmament, demobilization and reintegration (DDR): an assessment. Paper, World Congress of Political Science, $24^{\text {th }}$. Anais [], Poznan, julho de 2016.

SJOBERG, Laura; VIA, Sandra. Gender, war and militarism: feminist perspectives. California: Praeger Security International, 2010. 282p.

WEITSMAN, Patricia A. The Politics of Identity and Sexual Violence: A Review of Bosnia and Rwanda. Human Rights Quarterly, v. 30, n. 3, p. 561-578, 2008.

WARD, Jeanne; VANN, Beth; Gender-based violence in refugee settings. The Lancet, supl. Medicine and Conflict, v. 360, p. 13-14, 2002.

WOOD, Elisabeth J. Variation in Sexual Violence during War. Politics \& Society, v. 34, n. 3, p. 306-341, 2006.

WYATT, Edward. Security council calls for war crimes inquiry in Libya. 2011. Disponível em: http:// www.nytimes.com/2011/02/27/world/africa/27nations.html. Acesso em: 12 jul. 2017. 
1 Mestranda em Política Internacional pelo Programa de Pós-Graduação em Relações Internacionais da Universidade Federal de Santa Catarina. Graduada em Relações Internacionais pela Universidade Federal de Uberlândia. Desenvolve pesquisa nas áreas de direitos humanos, estudos de gênero e estudos de migração forçada, e na área de Teoria das Relações Internacionais, particularmente sobre pós-colonialismo, abordagens decoloniais e teorias feministas. E-mail: rafaelajulich@gmail.com

\section{(). (1) (2)}

Este artigo é licenciado na modalidade acesso abertosob a Atribuição-Compartilhalgual CC BY-SA

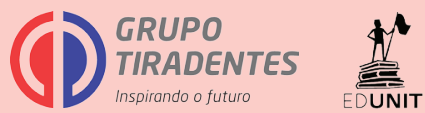

